\title{
MOLECULAR NETWORKING-BASED DEREPLICATION OF AMBUIC ACID DERIVATIVES FROM THE MARINE FUNGUS PESTALOTIOPSIS SP. 4A11
}

Luis C. Kellner Filho ${ }^{a}$, Rhenner N. A. Assis ${ }^{a}$, Aline O. dos Santos ${ }^{b}$, Sabrina K. Targanski ${ }^{c}$, Kátia A. Siqueira ${ }^{c}$, Livia S. de Medeiros $^{\mathrm{d}}$, Célio F. F. Angolini ${ }^{\mathrm{e}}$, Felipe M. A. da Silva ${ }^{\mathrm{b}}$, Marcos A. Soares ${ }^{\mathrm{c}}$, Gustavo M. Dias ${ }^{\mathrm{f}}$, Marcio L. A. Silva ${ }^{\mathrm{a}}$, Wilson R. Cunha a , Patricia M. Paulettia , Hector H. F. Koolen ${ }^{\mathrm{b}, \#}$ and Ana H. Januario ${ }^{\mathrm{a}, *, \mathbb{}}$

a Núcleo de Pesquisa em Ciências Exatas e Tecnológicas, Universidade de Franca, 14404-600 Franca - SP, Brasil

${ }^{b}$ Grupo de Pesquisa em Metabolômica e Espectrometria de Massas, Universidade do Estado do Amazonas, 69050-010 Manaus - AM, Brasil

'Instituto de Biociências, Universidade Federal de Mato Grosso, 78060-900, Cuiabá - MT, Brasil

${ }^{\text {d} D e p a r t a m e n t o ~ d e ~ Q u i ́ m i c a, ~ U n i v e r s i d a d e ~ F e d e r a l ~ d e ~ S a ̃ o ~ P a u l o, ~ 09920-540 ~ D i a d e m a ~-~ S P, ~ B r a s i l ~}$

${ }^{\mathrm{e}}$ Centro de Ciências Naturais e Humanas, Universidade Federal do ABC, 09210-580 Santo André - SP, Brasil

${ }^{\mathrm{f} C e n t r o ~ d e ~ C i e ̂ n c i a s ~ N a t u r a i s ~ e ~ H u m a n a s, ~ U n i v e r s i d a d e ~ F e d e r a l ~ d o ~ A B C, ~ 09606-070 ~ S a ̃ o ~ B e r n a r d o ~ d o ~ C a m p o ~-~ S P, ~ B r a s i l ~}$

Recebido em 19/05/2021; aceito em 24/08/2021; publicado na web em 15/09/2021

\begin{abstract}
Ambuic acid (AA) is a highly-modified cyclohexenone and known as a promising inhibitor of quorum sensing in methicillinresistant Staphylococcus aureus, and is thus a candidate as an antivirulence drug. This molecule is mainly produced by the species of Pestalotiopsis and, since its discovery twenty years ago, only a restricted amount of AA-derivatives have been described. Despite being a promising subject, methods for the analysis of modified AA-analogues via mass spectrometry remain unexplored. In order to adress this question, the marine fungus Pestalotiopsis sp. 4A11 associated with the ascidian Didemnum perlucidum was grown in a solid rice medium and its crude extract was chemically studied. From this extract, AA and 10-hydroxy ambuic acid (10-HAA) were isolated and identified using NMR spectroscopy with the aim of obtaining model compounds for the MS analysis. These served as reference compounds (seeds) to guide the dereplication of other AA-analogues via LC-MS/MS-based molecular networking. Based on the manual interpretation of the fragmentation pathways of the seeds and related compounds observed in the networks, six AA-derivatives were dereplicated in the extract. Furthermore, three analogues with unprecedented chemical formulas were proposed as putative unprecedented AA-derivatives. The fragmentation annotation proposed represents a fast and feasible method for characterizing AA-derivatives.
\end{abstract}

Keywords: ambuic acid; Ascidiaceae; Didemnum perlucidum; molecular networking; Pestalotiopsis sp.

\section{INTRODUCTION}

Pestalotiopsis species (Pestalotiopsidaceae) are Ascomycetes that are widely distributed worldwide and are usually associated with plants in the marine environment ${ }^{1-3}$ and with soil, where they act as saprobes. ${ }^{4}$ Some species are known pathogens, especially $P$. versicolor and $P$. theae, whose infections cause economic losses. ${ }^{5}$ After several taxonomical (morphology and genetic) re-analysis with within to date, 368 Pestalotiopsis species have been cataloged in the fungus database index Fungorum (http://www.indexfungorum.org/ Names/Names.asp).

The interest in studying species of Pestalotiopsis increased after the anticancer molecule taxol was isolated from an endophytic strain of P. microspora ${ }^{6,7}$ Another reason for this great interest in these species is the structural diversity of their active compounds, which includes alkaloids, polyketides, terpenoids, and peptides. ${ }^{4,8,9}$ Among these compounds, ambuic acid (AA) and its derivatives stand out. ${ }^{10-13}$ Ambuic acid and its derivatives are highly functionalized cyclohexenones with a moiety that resembles the moiety found in tetracycline. These compounds display potent antifungal activity against plant pathogens. For example, $\mathbf{A A}$ is active against Pythium ultimum $(\mathrm{MIC}=7.5 \mu \mathrm{g} / \mathrm{mL}) .{ }^{10}$

Some of these compounds can inhibit nitric oxide, which makes them potential anti-inflammatory agents. ${ }^{13}$ Other compounds of this class exert antimicrobial action against the Gram-positive bacterium Staphylococcus aureus. For Gram-positive bacterial pathogens, virulence is most often regulated via the accessory gene regulator (agr) quorum sensing system, and is thus a promising target for broad-spectrum antivirulence agents in quorum sensing signal biosynthesis. Todd et al. ${ }^{14}$ found that $\mathbf{A A}$ inhibits autoinducing peptide (AIP) biosynthesis in a USA300 MRSA strain $\left(\mathrm{IC}_{50}=\right.$ $\left.2.5 \pm 0.1 \mu \mathrm{mol} \mathrm{L} \mathrm{L}^{-1}\right)$, and that this acid presents potent activity against multiple bacterial pathogens in vitro, e.g., S. epidermidis, Enterococcus faecalis, Listeria monocytogenes, S. saprophyticus, and S. lugdunensis. However, this acid does not inhibit quorum sensing in commensal bacteria. These findings pointed to the AA potential as a lead compound for the development of broad-spectrum agents for antivirulence therapeutics. ${ }^{14,15}$

Herein, we have isolated the Pestalotiopis sp. 4A11 strain from the ascidian Didemnum perlucidum. After cultivation in rice medium, in the ethyl acetate extract of this fungal species, we detected AA and 10 other derivatives as the main constituents, among which compounds 10-hydroxy ambuic acid (10-HAA) and AA predominated. Compounds 1-9 were characterized by extensive mass spectrometry analysis. The major variations in the $\mathbf{A A}$ backbone included oxidation reactions in the $\mathrm{C}$-linked side chain or reduction of the $\mathrm{C} 11$ double bond or $\mathrm{C} 10$ carbonyl in the cyclohexenone ring, as shown in Figure 1.

*e-mail: ana.januario@unifran.edu.br

\#e-mail alternativo: hectorkoolen@gmail.com 
<smiles>[Y]CCCC/C=C\C1=C(CO)[C@H](O)[C@@H]2O[C@@]2(C/C=C(/C)C(=O)O)C1[R]</smiles>

$9 \mathrm{R}=\alpha-\mathrm{OH}$

$11 \mathrm{R}=\mathrm{O}$

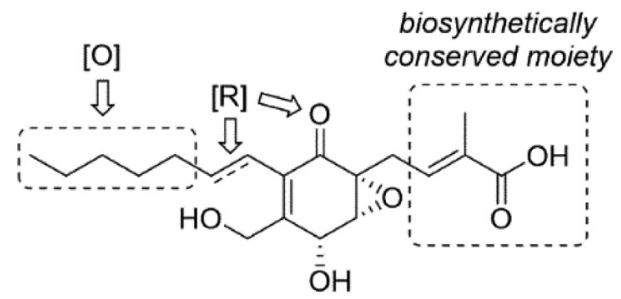

ambuic acid (AA) derivative

Figure 1. Chemical structures of the isolated reference compound ambuic acid $(\boldsymbol{A A})$ and its 10-hydroxy analogous compound (10-HAA) and general plausible biosythetic modifications

\section{EXPERIMENTAL}

\section{General experimental procedures}

Specific optical rotations were measured with a polarimeter (P-2000, Jasco digital, Japan). 1D and 2D NMR experiments were conducted in $\mathrm{CD}_{3} \mathrm{OD}$ at $293 \mathrm{~K}$ on a spectrometer (DRX-500 NMR, Bruker, USA) operating at $11.75 \mathrm{~T}\left({ }^{1} \mathrm{H}\right.$ and ${ }^{13} \mathrm{C}$ at 500 and $125 \mathrm{MHz}$, respectively). The chemical shifts $(\delta)$ are presented in ppm relative to the solvent signal ( $\left.\mathrm{CD}_{3} \mathrm{OD}: \delta \mathrm{H} 3.31 \mathrm{ppm}, \delta \mathrm{C} 49.00 \mathrm{ppm}\right)$ as the internal reference. LC-MS analysis was performed on a LC-MS system (iFunnel Q-ToF 6550, Agilent, USA). The HPLC separations were carried out on an analytical C18 column (Gemini ODS column $250 \times 4.6 \mathrm{~mm}, 5 \mu \mathrm{m}$; Phenomenex) with a precolumn. The mobile phase consisted of $0.1 \%$ formic acid solution (A) and $\mathrm{MeOH}+$ $0.1 \%$ formic acid (B). Elution started with A, which was followed by a gradient of $5 \%$ to $100 \% \mathrm{~B}$ for $40 \mathrm{~min}$ and maintenance of $100 \%$ B for $5 \mathrm{~min}$; the flow rate was $350 \mu \mathrm{L} / \mathrm{min}$. The column was re-equilibrated in 5\% B for $5 \mathrm{~min}$. Analytical HPLC was performed on a binary system (LC-20AD, Shimadzu Prominence, Japan) equipped with a series diode array detector (SPD-20A, Shimadzu, Japan), an autosampler (SIL-20A HT, Shimadzu, Japan), a column oven (CTO-20A, Shimadzu, Japan), and a degasser (DGU-20A-5, Shimadzu, Japan). A Gemini ODS column $(250 \times 4.6 \mathrm{~mm}, 5 \mu \mathrm{m}$; Phenomenex) with a precolumn was applied in the purification steps. Preparative HPLC analysis was conducted on a binary system (LC$6 \mathrm{AD}$, Shimadzu, Japan) equipped with a semipreparative column $(250 \times 10 \mathrm{~mm}, 5 \mu \mathrm{m})$. Column chromatography was performed on silica gel (Sigma-Aldrich, 70-230 mesh). TLC analysis (analytical and preparative) was carried out by using precoated silica gel 60 F254 plates ( $0.25 \mathrm{~mm}$; Sigma-Aldrich), and the spots were visualized by exposure to UV254/365 light; the plates were sprayed with $p$-anisaldehyde, which was followed by heating on a plate, or with sulfuric vanillin. The analytical solvents were of analytical (Synth) or HPLC (J.T. Baker) grade.

\section{Fungal material}

The Pestalotiopsis sp. 4A11 strain was isolated from the ascidian Didemnum perlucidum, which was collected in Ilhabela, São
Paulo, Brazil in September 2015 by Gustavo M. Dias. The fungus was identified as Pestalotiopsis sp. by a $16 \mathrm{~S}$ rRNA gene sequence (GenBank No. MN044718). The fungus was cultured at $25^{\circ} \mathrm{C}$ for 30 days in $5 \times 500 \mathrm{~mL}$ Erlenmeyer flasks. Each of the flasks contained rice $(200.0 \mathrm{~g})$, and a nutrient solution $\left(1.2 \mathrm{~g}\right.$ of $\mathrm{NaNO}_{3}, 0.4 \mathrm{~g}$ of $\mathrm{KH}_{2} \mathrm{PO}_{4}, 0.2 \mathrm{~g}$ of $\mathrm{MgSO}_{4} .7 \mathrm{H}_{2} \mathrm{O}, 0.2 \mathrm{~g}$ of $\mathrm{KCl}$ and traces of $\mathrm{FeSO}_{4}$ dissolved in $400 \mathrm{~mL}$ of distilled water).After the fungus had grown, the whole material was extracted twice with EtOAc $(300 \mathrm{~mL}$ per flask) for $24 \mathrm{~h}$. The solvent was evaporated under reduced pressure to give the EtOAc extract $(6.25 \mathrm{~g}, 0.62 \%$, w/w $)$.

\section{Isolation of the compounds}

Part of the EtOAc extract (1.0 g) was subjected to silica gel ( $30 \mathrm{~g}$, 70-230 mesh) column chromatography. The mobile phase consisted of a hexane/EtOAc gradient (95:5 to 0:100, v/v), which was followed by isocratic elution with $\mathrm{MeOH}(100 \%)$, to yield seven fractions (Fr. 1-7). Fr. 5 (113 mg), which was eluted with hexane/EtOAc $(1: 1, \mathrm{v} / \mathrm{v})$, was purified by semipreparative HPLC in the isocratic mode with $70 \% \mathrm{MeOH}$ solution at $4.5 \mathrm{~mL} \mathrm{~min}^{-1}$ and $\lambda_{\max }=254 \mathrm{~nm}$, to give AA (16.1 mg). Fr. 6 (165 mg, EtOAc 100\%) was further separated by semipreparative HPLC $(65 \% \mathrm{MeOH}$ solution, isocratic mode, $\left.4.5 \mathrm{~mL} \mathrm{~min}^{-1}, \lambda_{\max }=254 \mathrm{~nm}\right)$, to yield 10-HAA $(14.6 \mathrm{mg})$.

\section{Toxicity in different model organisms}

The toxicity of compounds AA and 10-HAA was evaluated in Galleria mellonella, Caenorhabditis elegans, and Tetrahymena pyriformis larvae. The G. mellonella larvae were kept in the laboratory, and 10 larvae were selected (body mass $0.2-0.3 \mathrm{~g}$ ). ${ }^{16} \mathrm{~A}$ volume of $10 \mu \mathrm{L}$ of the solutions $(4 \mathrm{mg} / \mathrm{mL})$ was injected into the larvae, and the percentage of mortality was assessed seven days later. ${ }^{17}$ T. pyriformis cells $(10,000$ cells $/ \mathrm{mL})$ were treated with the compounds and the number of cells was counted $48 \mathrm{~h}$ later. ${ }^{18}$ The L4 populations of $C$. elegans $\mathrm{N} 2$ were synchronized, ${ }^{19}$ and toxicity was assessed $24 \mathrm{~h}$ later. ${ }^{16}$ The negative controls consisted of a DMSO solution that was used to solubilize the extract and compounds. Except for the G. mellonella larvae, the tests were carried out with the compounds at a concentration of $0.5 \mathrm{mg} / \mathrm{mL}$ and with the crude extract at a concentration of $0.2 \mathrm{mg} / \mathrm{mL}$.

\section{RESULTS AND DISCUSSION}

\section{Ambuic acid characterization}

As the starting point, the isolated compounds identified as $\mathbf{A A}^{10}$ and 10-HAA ${ }^{13}$ served as reference compounds to guide the dereplication workflow. The chemical structure of ambuic acid is well established in the literature 2D-NMR, and includes studies of total synthesis, which support its absolute stereochemistry. ${ }^{20-22}$ In this work, the relative stereochemistry of both isolated compounds was proposed by comparing the spectroscopic data and the optical rotation data with those in the literature. ${ }^{10,13}$ As such, AA served as the main "seed" molecule in the dereplication steps.

The principal ionic species in the mass spectrum of $\mathbf{A A}$ (Supplementary Material) were its ammonium $\left[\mathrm{M}+\mathrm{NH}_{4}\right]^{+}$ $\left(\mathrm{m} / \mathrm{z}, 368.2078 ; \Delta_{m / z}\right.$ theoretical $\left.=1.1 \mathrm{ppm}\right)$ and sodium $[\mathrm{M}+\mathrm{Na}]^{+}$ $\left(\mathrm{m} / \mathrm{z}\right.$ 373.1639; $\Delta_{m / z}$ theoretical $\left.=3.2 \mathrm{ppm}\right)$ adducts. Additionally, the protonated molecule $[\mathrm{M}+\mathrm{H}]^{+}$emerged as a low-abundance ion. The MS/MS spectra of the $[\mathrm{M}+\mathrm{H}]^{+}$and $\left[\mathrm{M}+\mathrm{NH}_{4}\right]^{+}$species were quite similar, an observation that helped to study this compound and other molecules related to ambuic acid, especially when the $[\mathrm{M}+\mathrm{H}]^{+}$ion was not intense enough to be fragmented (Supplentary 
Information). In order to conduct the tentative structural assigments of the directly connected and/or proximal nodes of this compound, we analyzed the product ion spectrum of $\mathbf{A A}$ and interpreted its gas phase fragmentation behaviour by means of a logical fragmentation pathway (Figure 2). Initially, sequential water losses $\left(\mathrm{H}_{2} \mathrm{O},-18.01 \mathrm{u}\right)$ occurred in competition with carbon monoxide losses $(\mathrm{CO},-27.99$ u). For this, we proposed that the proton from ionization must have been placed at the epoxide of the cyclohexenone system, which was possibly facilitated by a gas-phase proton migration. Thereafter, acidic epoxide opening yielded a resonance-stabilized vinyl cation that could undergo three consecutive water losses to give the stable product ions $m / z 333\left([\mathrm{M}+\mathrm{H}]^{+} \rightarrow m / z 333\right), m / z 315(m / z 333 \rightarrow m / z \quad 315)$, and $m / z 297(m / z, 315 \rightarrow m / z$ 297). Moreover, the fragments were prone to carbon monoxide losses to afford the fragments $\mathrm{m} / z, 305$ $(\mathrm{m} / \mathrm{z} 333 \rightarrow \mathrm{m} / \mathrm{z} 305)$ and $\mathrm{m} / \mathrm{z} 287(\mathrm{~m} / \mathrm{z} 315 \rightarrow \mathrm{m} / \mathrm{z} 287)$. Interestingly, the product ion $\mathrm{m} / z 287.16$ may also originate from water loss from $\mathrm{m} / \mathrm{z} 305.17$, reinforcing the hypothesis of competitive fragmentation pathways for AA. Another observation regarding this behaviour was the product ion $\mathrm{m} / \mathrm{z}, 269$ (base peak), which may be formed via water loss from $m / z 287(\mathrm{~m} / \mathrm{z}, 287 \rightarrow \mathrm{m} / \mathrm{z} 269)$ or monoxide loss from $\mathrm{m} / \mathrm{z} 297$ $(\mathrm{m} / z, 297 \rightarrow \mathrm{m} / \mathrm{z}, 269)$

Besides the several high $\mathrm{m} / \mathrm{z}$, that were recorded, a region of clustered ions below $150 \mathrm{u}$ was recurrent in all the MS/MS spectra, which indicated useful diagnostic ions to detect $\mathbf{A A}$ analogous

A)

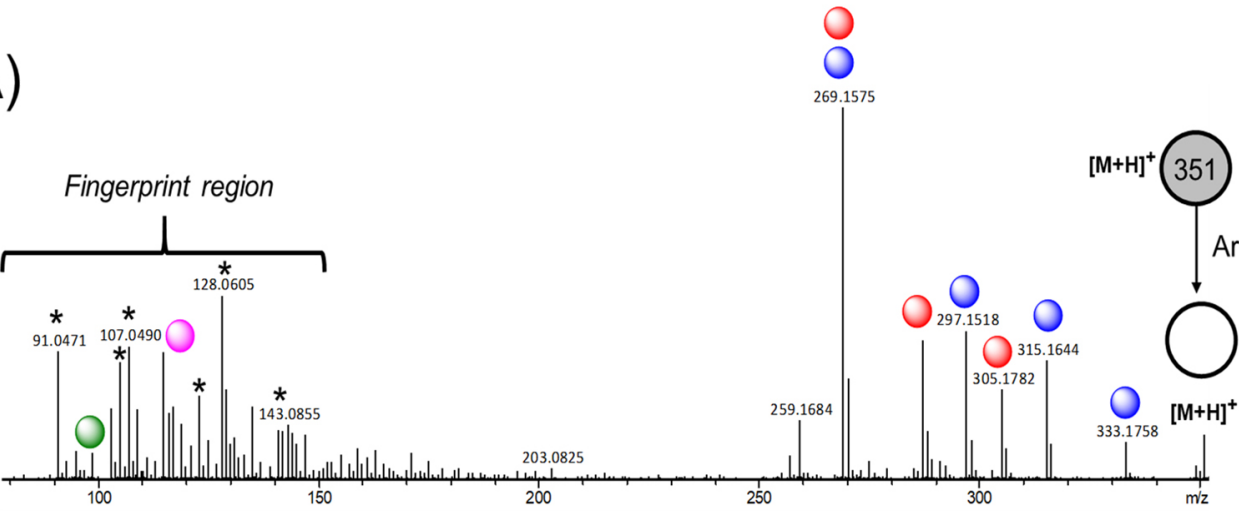

B)

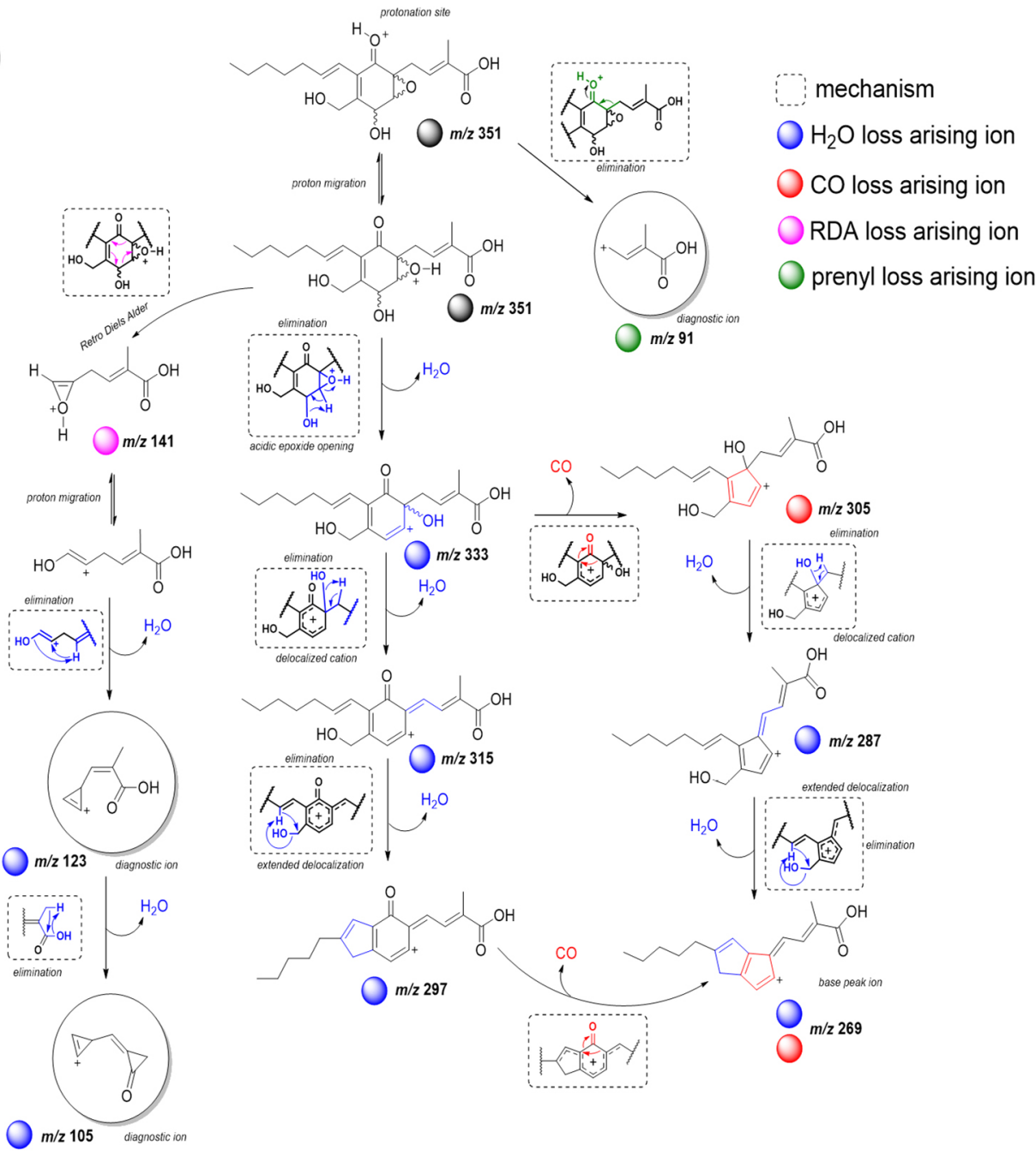

Figure 2. (A) Product ion spectrum of ambuic acid (AA). (B) Fragmentation pathway proposed on the basis of neutral losses obseved under CID conditions 
compounds, and thus provide partial interpretations. Given that all the selected precursor ions had fragments with the same $\mathrm{m} / \mathrm{z}$ in this region, we hypothesized that a core of the molecule was conserved in the different molecules observed in the crude extract. Although the biosynthesis of $\mathbf{A A}$ and its derivatives remains unkown, a search in the literature has shown that such molecules are rarely isolated, and that fewer than 30 derivatives have been described so far. Among the derivatives isolated, the moiety consisting of a carboxyl acid derivative of prenyl was conserved among all the previously-described $\mathbf{A A}$ derivatives. Therefore, we assigned the fragment $m / z, 99.04\left(\mathrm{C}_{5} \mathrm{H}_{7} \mathrm{O}_{2}{ }^{+}\right)$, consistent with a 2-methylbut-2-enoic acid cation, as a plausible diagnostic ion for AA derivatives. In addition, other fragments of this region of the spectrum were related to this conserved moiety. We proposed that a retro-Diels-Alder reaction (rDA) might occur in the cyclohexenone system, which would be followed by water loss and yield the fragment $m / z, 123.04\left(\mathrm{C}_{7} \mathrm{H}_{7} \mathrm{O}_{2}{ }^{+}\right)$, which is also a plausible diagnostic ion. Furthermore, we applied other ions, such as $m / z$ 91.04, $m / z$ 105.06, and $m / z$ 135.04, as diagnostic ions even though their structures remain unknown.

\section{Dereplication of ambuic acid derivatives}

To access the chemical repertoire of Pestalotiopsis sp. 4A11, we conducted LC-MS/MS analysis (Figure 3) (Table 1), and we constructed the corresponding molecular network with the converted MS/MS data. As a result, we were able to visualize several clusters of molecules from the full network (Figure 4). A concentrated cluster with more than 50 nodes revealed that other precursor ions in the experiments conducted under CID conditions displayed regular neutral losses and the same diagnostic ions as the ones observed in the MS/MS patterns of AA (seed ion). Apart from the seed node, several other nodes ressembling $[\mathrm{M}+\mathrm{H}]^{+}$ions bearing chemical formulas with suggestive $m / z$, shifts in relation to AA, such as $\Delta m / z+16 \mathrm{u}$ $(+\mathrm{O})$, indicated the presence of previously reported $\mathbf{A A}$ analogous compounds. ${ }^{11}$ Moreover, adduct ions (especially $\mathrm{M}+\mathrm{NH}_{4}$ ) emerged and, because their fragmentation behaviour mimicked the protonated molecules, we used them in the dereplication workflow.

The nodes of compounds 1 (rt $23.3 \mathrm{~min}, \mathrm{~m} / z 365.1596[\mathrm{M}+\mathrm{H}]^{+}$, $\Delta_{m / z}$ theoretical $\left.=-2.1 \mathrm{ppm}, \mathrm{C}_{19} \mathrm{H}_{24} \mathrm{O}_{7}\right)$ ), 2 (rt $25.0 \mathrm{~min}, \mathrm{~m} / \mathrm{z}, 367.1750$ $[\mathrm{M}+\mathrm{H}]^{+}, \Delta_{m / z}$ theoretical $\left.=-2.3 \mathrm{ppm}, \mathrm{C}_{19} \mathrm{H}_{26} \mathrm{O}_{7}\right)$.) and $\mathbf{3}(\mathrm{rt} 25.0 \mathrm{~min}$, $\mathrm{m} / \mathrm{z}, 367.1747[\mathrm{M}+\mathrm{H}]^{+}, \Delta_{m / z}$ theoretical $\left.=-1.6 \mathrm{ppm}, \mathrm{C}_{19} \mathrm{H}_{26} \mathrm{O}_{7}\right)$.) were observed surrounding the node corresponding to the seed AA. The literature review and the comparisons of the MS/MS profiles allowed us to propose the presence of AA-derivatives with higher degrees of oxidation. Analysis of the chemical formulas enabled us to propose 1 as 15-oxo or 16-oxo ambuic acids, since a $\Delta m / z$ of $+14 \mathrm{u}$ was observed in our data, which is consistent with the previous finding in the literature. ${ }^{11}$ Compounds 2 and $\mathbf{3} \Delta \mathrm{m} / z$ of +16 u related to the seed molecule, and thus hydroxylated analogues of AA. In particular, the node of $\mathbf{3}$ is directly connected to the seed node, in response to similar fragmentation behaviour of these compounds, thus reinforcing our proposals that $\mathbf{2}$ and $\mathbf{3}$ may be pestalotic acid analogues (pestalotic acids $\mathrm{G}, \mathrm{H}$, or I), as previously described. ${ }^{23}$

For compound 4 ( $\mathrm{rt} 25.4 \mathrm{~min}$ ), we deduced a chemical formula of $\mathrm{C}_{19} \mathrm{H}_{29} \mathrm{O}_{7}$ for the protonated molecule at $\mathrm{m} / z 369.1917\left([\mathrm{M}+\mathrm{H}]^{+}, \Delta_{m / z}\right.$ theoretical $=1.1 \mathrm{ppm}$ ). In addition, its product ion spectrum displayed the same diagnostic ions, along with sucessive neutral water losses and competitive carbon monoxide loss, which indicated the presence of a cyclohexenone system, as in the case of AA. However, the mass shift of $\Delta m / z$ of +18 u observed indicated that one extra hydroxyl group, along with a reduction site may be present in 4 . Interestingly, the search for $\mathbf{A A}$-analogues with the deduced formula did not result in any match. Therefore, we propose that $\mathbf{4}$ is a putative unprecedented analogue consistent with the epoxide being converted into a vicinal diol, as observed for pestallic acid $\mathrm{D},{ }^{24}$ but in contrast to this known compound since the ketone group at $\mathrm{C} 10$ is not reduced (Figure 4). ${ }^{13}$

Compounds 5 (rt $26.3 \mathrm{~min}, \mathrm{~m} / \mathrm{z} 384.2030\left[\mathrm{M}+\mathrm{NH}_{4}\right]^{+}$, $\Delta_{m / z}$ theoretical $\left.=2.1 \mathrm{ppm}\right)$ and $\mathbf{6}\left(\mathrm{rt} 27.2 \mathrm{~min}, \mathrm{~m} / z, 370.2235,\left[\mathrm{M}+\mathrm{NH}_{4}\right]^{+}\right.$, $\Delta_{m / z}$ theoretical $=1.6 \mathrm{ppm}$ ) displayed chemical profiles that are consistent with other compounds produced by Pestalotiopsis sp. 4A11. Particularly, compound 5 is consistent with the formula $\mathrm{C}_{19} \mathrm{H}_{26} \mathrm{O}_{7}$ and, since its fragmentation is similar to 2 , it was assumed to be a different isomer of a hydroxyl-AA derivative. On the other hand, compound 6 $\left(\mathrm{C}_{19} \mathrm{H}_{28} \mathrm{O}_{6}\right)$ was assigned as a plausible unknown diastereomer of compound 10-HAA, due to its similar fragmentations and closerelated molecular network nodes (Figure 4).

Compound 7 displayed an ammonium adduct ion $\mathrm{m} / \mathrm{z} 404.1840$ with an isotope pattern that was consistent with the presence of a chlorine atom in the structure. The formula deduced from the recorded $\mathrm{m} / z$ was $\mathrm{C}_{19} \mathrm{H}_{31} \mathrm{ClNO}_{6}$ (for the $\left[\mathrm{M}+\mathrm{NH}_{4}\right]^{+}$adduct, $\Delta_{m / z}$ theoretical $\left.=0.2 \mathrm{ppm}\right)$. The observed molecular formula was consistent with an $-16 \mathrm{u}$ analogous compound of the previously described AA-derivative microsporol A, which was isolated from an endophytic strain of Pestalotiopsis microspora. ${ }^{25}$ The absence of the protonated molecule ion and the presence of an intense $m / z 369.1467\left(\mathrm{C}_{19} \mathrm{H}_{28} \mathrm{ClO}_{5}\right.$ $\left(\left[\mathrm{M}+\mathrm{NH}_{4}-\mathrm{H}_{2} \mathrm{O}\right]^{+}, \Delta_{m / z}\right.$ theoretical $\left.=0.6 \mathrm{ppm}\right)$ indicated that, under CID conditions, the ammonium adduct yielded an intense $\left[\mathrm{M}-\mathrm{H}_{2} \mathrm{O}\right]^{+}$ fragment ion via sequential ammonia $(-17.03 \mathrm{u})$ and water losses. Additionally, this phenomenon was observed in the MS spectrum, which reinforced the ideia that the adduct was unstable, thus leading to in-source fragmentation. Furthermore, sequential ammonia/water loss with subsequent water losses from an ammonium adduct have previously been observed during $\mathrm{ESI}^{26}$ and chemical ionization $(\mathrm{CI})^{27}$ analyses. This occurred because the proton affinity (PA) of compound 7 relative to $\mathrm{PA}\left(\mathrm{NH}_{3}\right)$ strongly influenced the competition between the protonation and nucleophilic substitution processes. Since compound $\mathbf{7}$ has lower PA than ammonia, direct formation of $[\mathrm{M}+\mathrm{H}]^{+}$will not occur, but ammonia will be eliminated to give unstable hydroxyl protonated molecules that are susceptible to water losses (Figure 5). ${ }^{26}$

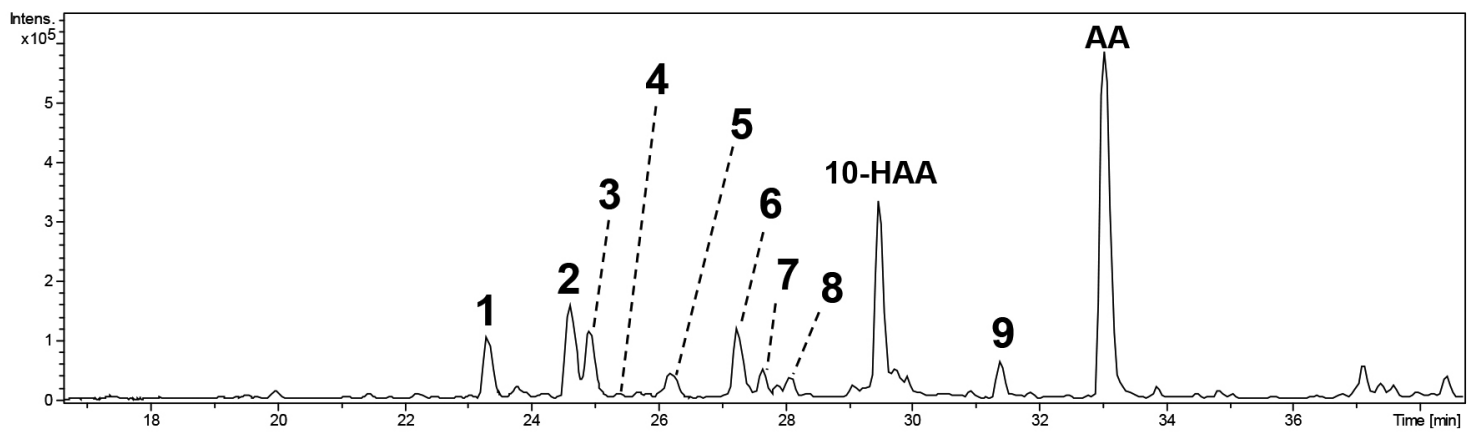

Figure 3. Total ion chromatogram of the Pestalotiopsis sp. 4 A11 EtOAc extract 


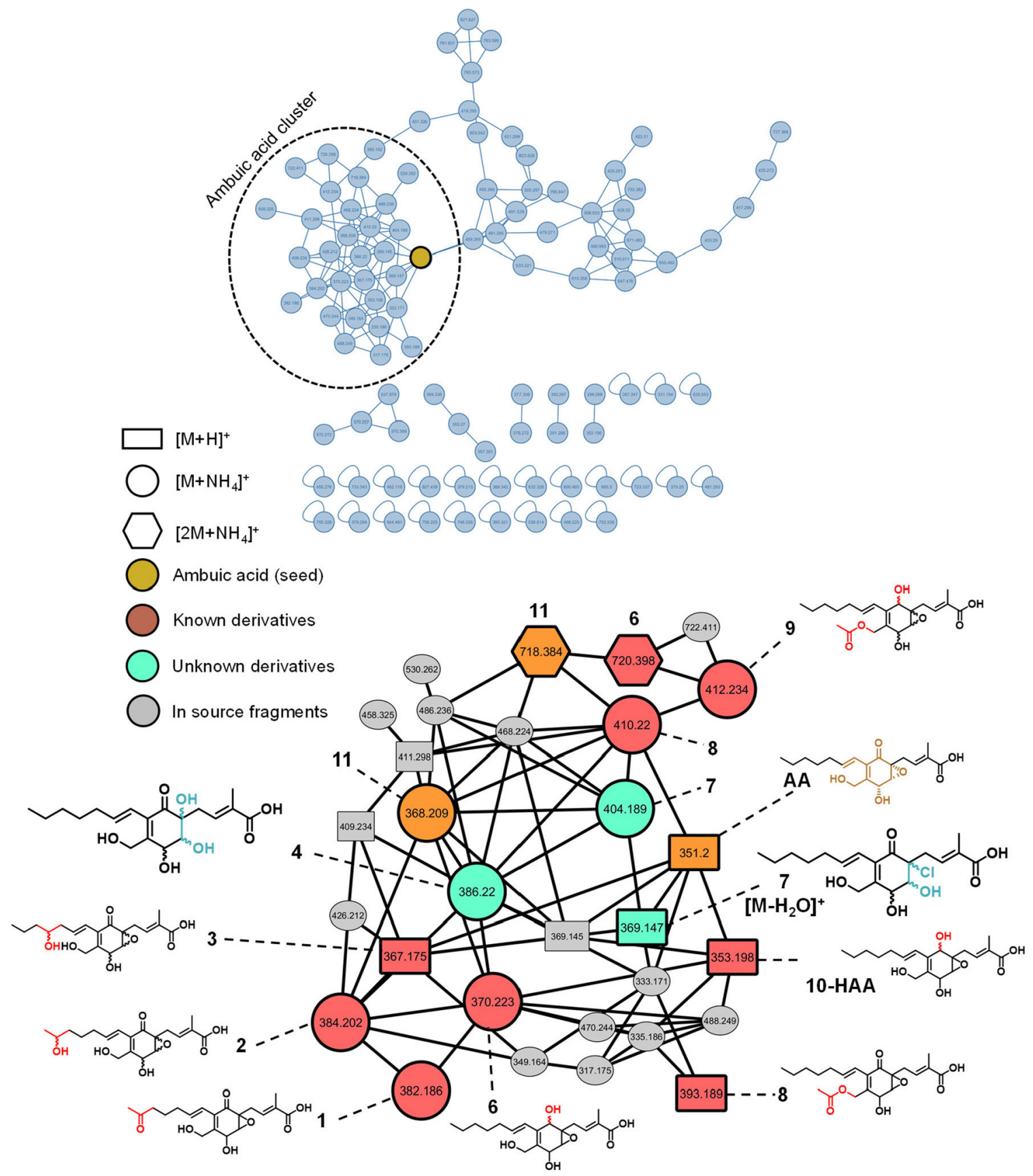

Figure 4. (A) General view of the molecular networking of the EtOAc extract obtained from Pestalotiopsis sp. 4A11. (B) Annotation of the molecular networking region recognized as a cluster of ambuic acid derivatives, which shows the seed ambuic acid derivatives (orange nodes), known ambuic acid derivatives (red dots), and plausible unknown analogous compounds (green dots). Silver dots represent in-source fragment ions, and/or chimeric ions

Furthermore, the fragmentation behaviour of compound 7 was consistent with the behaviour that has previously been observed for AA derivatives, including the diagnostic ions. Initially, the fragment $\mathrm{m} / \mathrm{z}, 369$ underwent a water loss to give the key intermediate $\mathrm{m} / \mathrm{z}, 351$ $(m / z, 369 \rightarrow m / z, 351)$ (Figure 5). Then, the latter product ion could follow two distinct pathways: one of them involving chlorine atom conservation, and the other involving its neutral loss. The proposal of these two possibilities was supported through inspection of the isotope pattern distributions for each product ion of the MS/MS spectrum (Supplementary Material). In the first pathway, a water loss $(\mathrm{m} / \mathrm{z}, 351 \rightarrow \mathrm{m} / \mathrm{z}, 333)$ was followed by a competitive carbon monoxide $(\mathrm{m} / \mathrm{z} 333 \rightarrow \mathrm{m} / \mathrm{z}, 305)$ or carbon dioxide $(-44.01 \mathrm{u}, \mathrm{m} / \mathrm{z}$ $333 \rightarrow m / z$ 289) losses. In the second pathway, sequential losses of hydrochloric acid $(-35.98 \mathrm{u}, \mathrm{m} / \mathrm{z}, 351 \rightarrow \mathrm{m} / \mathrm{z}, 315)$ and water $(\mathrm{m} / \mathrm{z}$
$315 \rightarrow m / z$ 297) took place (Figure 5). Our findings indicate that this compound may be proposed as the putative deoxy-derivative of microsporol A (Figure 4).

Furthermore, compounds 8 (rt $28.2 \mathrm{~min}, \mathrm{~m} / \mathrm{z} 393.1913[\mathrm{M}+\mathrm{H}]^{+}$, $\Delta_{m / z}$ theoretical $\left.=0.1 \mathrm{ppm}, \mathrm{C}_{21} \mathrm{H}_{28} \mathrm{O}_{7}\right)$ and $9(\mathrm{rt} 31.4 \mathrm{~min}, \mathrm{~m} / \mathrm{z}, 412.2337$ $\left[\mathrm{M}+\mathrm{NH}_{4}\right]^{+}, \Delta_{m / z}$ theoretical $\left.=0,5 \mathrm{ppm}, \mathrm{C}_{21} \mathrm{H}_{30} \mathrm{O}_{7}\right)$ displayed chemical formulas that are consistent with acetyl-derivatives (+ $42 \mathrm{u}$ ) of AA and 10-HAA, respectively (Figure 4). Despite being acetylated, their fragmentation profiles were similar to the isolated analogues, but with the absence of typical acetyl losses. The proposal is consitent with previously isolated acetyl derivatives that, so far, are restricted to the C-19 position. ${ }^{11,13,23}$ Therefore, a total of nine AA-derivatives were assigned by mass spectrometry. 


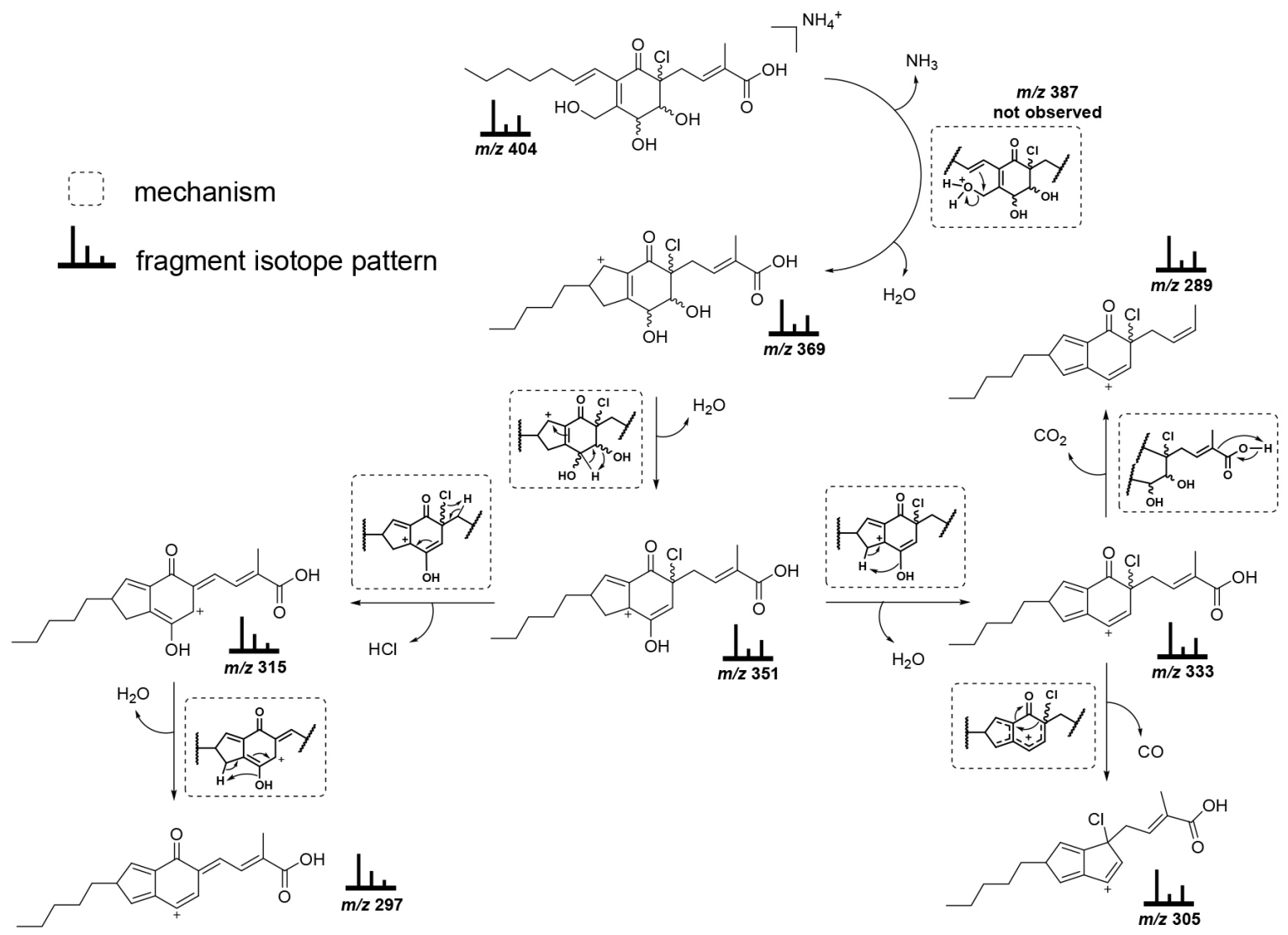

Figure 5. Plausible fragmentation pathway of the unknown analogous compound 7

Table 1. Chemical composition of ambuic acid derivatives produced by Pestalotiopsis sp. 4A11

\begin{tabular}{lcccc}
\hline Compound & $\mathrm{rt}$ & {$[\mathrm{M}+\mathrm{H}]^{+}$(error) } & {$\left[\mathrm{M}+\mathrm{NH}_{4}\right]^{+}$(error) } & Chemical formula \\
\hline $\mathbf{1}$ & 23.3 & $365.1596(-1.1)$ & $382.1857(-2.1)$ & $\mathrm{C}_{19} \mathrm{H}_{24} \mathrm{O}_{7}$ \\
$\mathbf{2}$ & 24.6 & $367.1750(-1.6)$ & $384.2013(-2.3)$ & $\mathrm{C}_{19} \mathrm{H}_{26} \mathrm{O}_{7}$ \\
$\mathbf{3}$ & 25.0 & $367.1747(-2.4)$ & $384.2016(-1.6)$ & $\mathrm{C}_{19} \mathrm{H}_{26} \mathrm{O}_{7}$ \\
$\mathbf{4}$ & 25.4 & $369.1917(+1.1)$ & - & $\mathrm{C}_{19} \mathrm{H}_{28} \mathrm{O}_{7}$ \\
$\mathbf{5}$ & 26.3 & - & $384.2030(+2.1)$ & $\mathrm{C}_{19} \mathrm{H}_{26} \mathrm{O}_{7}$ \\
6 & 27.2 & $353.1960(-1.1)$ & $370.2235(+1.6)$ & $\mathrm{C}_{19} \mathrm{H}_{28} \mathrm{O}_{6}$ \\
$\mathbf{7}$ & 27.6 & - & $404.1840(+0.2)$ & $\mathrm{C}_{19} \mathrm{H}_{27} \mathrm{ClO}_{6}$ \\
$\mathbf{8}$ & 28.2 & $393.1913(+0.1)$ & - & $\mathrm{C}_{21} \mathrm{H}_{28} \mathrm{O}_{7}$ \\
$\mathbf{1 0 - H A A}$ & 29.4 & - & $370.2229(+0.1)$ & $\mathrm{C}_{19} \mathrm{H}_{28} \mathrm{O}_{6}$ \\
$\mathbf{9}$ & 31.4 & - & $412.2337(+0.5)$ & $\mathrm{C}_{21} \mathrm{H}_{30} \mathrm{O}_{7}$ \\
$\mathbf{A A}$ & 32.9 & - & $368.2078(+1.1)$ & $\mathrm{C}_{19} \mathrm{H}_{26} \mathrm{O}_{6}$ \\
\hline
\end{tabular}

\section{Biological evaluation}

Interest in employing the G. mellonella model in in vivo toxicity tests has increased over the years because it is practical and also because the larva of this insect is an excellent model organism for in vivo toxicology and pathogenicity experiments given that the immune response of this insect resembles the immune response of mammals. ${ }^{28}$ Concerning the nematode $C$. elegans, this worm stands out as a model organism due to its attributes such as simplicity, transparency, short life cycle, and low cost. Toxicity tests using C. elegans can provide data on an entire animal with active and metabolized systems. Finally, the protozoan T. pyriformis is a nonpathogenic freshwater ciliate with well-known physiology and biochemistry. This ciliate presents receptors and secondary messenger systems that highly resemble these systems in vertebrates, not to mention that they are easy to handle in experiments, making them an excellent unicellular model for toxicological investigation. ${ }^{17}$ The consistent correlations of the three selected assays justify their inclusion in safety tests prior to mammal tests for risk assessment. ${ }^{18}$ To our knowledge, toxicity data for compounds 10-HAA and AA are not yet available. In our studies, the AA, 10-HAA and EtOAc extract when evaluated in the three proposed alternative toxicity tests using G. mellonella, C. elegans, and T. pyriformis showed no toxicity.

The non-toxic profile contributes to the possible future application of these compounds as therapeutic agents.

\section{CONCLUSIONS}

The combination of LC-MS/MS analysis with molecular networking data interpretation, shed light on the molecules that 
could not be identified in regular isolation workflows. By means of manual interpretation of the MS/MS spectra, we have dereplicated nine AA derivatives that had previously been identified in other Pestalotiopsis species, or that represent possible new compounds. It is worth noting that the designation of new natural molecules may only be unequivocally possible with NMR data of isolated compounds. Moreover, our findings indicate that MS-based analysis of crude fungal extracts can provide valuable information that can aid when deciding the further isolation workflow and/or help during the isolation process via a MS-guided strategies.

\section{SUPPLEMENTARY MATERIAL}

NMR and MS spectra are available free of charge at http:// quimicanova.sbq.org.br as a PDF file.

\section{ACKNOWLEDGMENTS}

The authors would like to thank the Coordenação de Aperfeiçoamento de Pessoal de Nível Superior - Brasil (CAPES Grant \# 23038.009588/2013-68 CSF-PVEs 27/2014 and Finance Code 001), Conselho Nacional de Desenvolvimento Científico e Tecnológico (CNPq, Grant \# 302340/2018-1), and Fundação de Amparo à Pesquisa do Estado de São Paulo (FAPESP, Grants \# 2014/19184-7 and 2017/14261-1 ) for their support and funding. H. H. F. Koolen thanks the Fundação de Amparo à pesquisa do Estado do Amazonas (FAPEAM). M. A. Soares thanks the Fundação de Amparo à Pesquisa do Estado de Mato Grosso (FAPEMAT, Grant \# 583867/2016) We also thank the Yacht Clube de Ilhabela and Centro de Biologia Marinha da USP (CEBIMar) for their logistical support.

\section{REFERENCES}

1. Menezes, C. B. A.; Bonugli-Santos, R. C.; Miqueletto, P. B.; Passarini, M. R. Z.; Silva, C. H. D.; Justo, M. R.; Leal, R. R.; FantinattiGarboggini, F.; Oliveira, V. M.; Berlinck, R. G. S.; Sette, L. D.; Microbiol. Res. 2010, 165, 466.

2. Kumar, A.; Sørensen, J. L.; Hansen, F. T.; Arvas, M.; Syed, M. F.; Hassan, L.; Benz, J. P.; Record, E.; Henrissat, B.; Pöggeler, S.; Kempken, F.; Sci. Rep. 2018, 8, 1.

3. Lei, H.; Lin, X.; Han, L.; Ma, J.; Dong, K.; Wang, X.; Zhong, J.; Mu, Y.; Liu, Y.; Huang, X.; Phytochemistry 2017, 142, 5.

4. Deshmukh, S. K.; Prakash, V.; Ranjan, N.; Phytochem. Rev. 2017, 16, 883.
5. Strobel, G.; J. Fungi 2018, 4, 57.

6. Strobel, G. A.; Hess, W. M.; Ford, E.; Sidhu, R. S.; Yang, X.; J. Ind. Microbiol. Biotechnol. 1996, 17, 417.

7. Yang, X-L.; Zhang, J-Z.; Luo, D-Q.; Nat. Prod. Rep. 2012, 29, 622.

8. Xu, J.; Ebada, S. S.; Proksch, P.; Fungal Divers. 2010, 44, 15.

9. Wang, K.; Lei, J.; Wei, J.; Yao, N.; Mini-Reviews Med. Chem. 2012, 12, 1382.

10. Li, J. Y.; Harper, J. K.; Grant, D. M.; Tombe, B. O.; Bashyal, B.; Hess, W. M.; Strobel, G. A.; Phytochemistry 2001, 56, 463.

11. Ding, G.; Li, Y.; Fu, S.; Liu, S.; Wei, J.; Che, Y.; J. Nat. Prod. 2009, 72, 1368.

12. Xie, J.; Li, J.; Yang, Y. H.; Chen, Y. H.; Zhao, P. J.; Phytochem. Lett. 2014, 10, 291.

13. Qi, Q. Y.; Li, E. W.; Han, J. J.; Pei, Y. F.; Ma, K.; Bao, L.; Huang, Y.; Zhao, F.; Liu, H. W.; Sci. Rep. 2015, 5, 9958.

14. Todd, D. A.; Parlet, C. P.; Crosby, H. A.; Malone, C. L.; Heilmann, K. P.; Horswill, A. R.; Cech, N. B.; Antimicrob. Agents Chemother. 2017, 61,1 .

15. Horswill, A. R.; Gordon, C. P.; J. Med. Chem. 2020, 63, 2705.

16. Sousa, J. R.; Silva, F. A.; Targanski, S. K.; Fazolo, B. R.; Souza, J. M.; Campos, M. G.; Vieira, L. C. C.; Mendes, T. A. O.; Soares, M. A.; J. Appl. Entomol. 2019, 143, 1172.

17. Harding, C. R.; Schroeder, G. N.; Collins, J. W.; Frankel, G.; J Vis Exp. 2013, 81, e50964.

18. Maurya, R.; Dubey, K.; Singh, D.; Jain, A. K.; Pandey, A. K.; Ecotoxicol. Environ. Saf. 2019, 182, 109375.

19. Porta-de-la-Riva, M.; Fontrodona, L.; Villanueva, A.; Cerón, J.; J. Vis. Exp. 2012, 64, e4019 10.3791/4019.

20. Li, C.; Johnson, R. P.; Porco, J. A.; J. Am. Chem. Soc. 2003, 125, 5095.

21. Mehta, G.; Pan, S. C.; Tetrahedron Lett. 2005, 46, 3045.

22. Jung, S. H.; Hwang, G-S.; Lee, S.; Ryu, D. H.; J. Org. Chem. 2012, 77, 2513 .

23. Li, J.; Xie, J.; Yu, F. X.; Chen, Y. H.; Zhao, P. J.; Arch. Pharm. Res. 2016, 39,1 .

24. Li, C.S.; Yang, B.J.; Turkson, J.; Cao, S.; Phytochemistry 2017, 140, 77.

25. Wu, X.; Wang, Y.; Liu, S.; Liu, X.; Guo, L.; Nat. Prod. Commun. 2015, $10,1643$.

26. Madhusudanan, K. P. J. Mass Spectrom. 2006, 41, 1096.

27. Despeyroux, D.; Cole, R. B.; Tabet, J. C.; Org. Mass Spectrom. 1992, 27,300 .

28. Ignasiak, K.; Maxwell, A.; BMC Res. Notes 2017, 10, 428. 